\title{
Aphis gossypii (Hemiptera: Aphididae) as a factor inhibiting the survival and population increase of the predator Macrolophus pygmaeus (Hemiptera: Miridae) on cucumber
}

\author{
Dionyssios C. PERDIKIS and Dionyssios P. LYKOURESSIS* \\ Agricultural University of Athens, Laboratoty of Agricultural Zoology and Entomology, 75 Iera Odos, 11855 Athens, Greece; \\ e-mail: lykouressis@aua.gr
}

Key words. Macrolophus pygmaeus, life table, Aphis gossypii, cucumber, honeydew, predator

\begin{abstract}
The influence of cucumber offered as a host plant either alone or with Aphis gossypii Glover (Hemiptera: Aphididae) was studied on the various life table and biological characteristics of the predatory bug Macrolophus pygmaeus Rambur (Hemiptera: Miridae). The nymphal development was studied at $15,20,25,30$ and $35^{\circ} \mathrm{C}$ while adult performance was assessed at $15,20,25$ and $30^{\circ} \mathrm{C}$, using a $16 \mathrm{~L}: 8 \mathrm{D}$ photoperiod and $65 \pm 5 \%$ r.h. Nymphs completed their development at all temperatures except at $35^{\circ} \mathrm{C}$. Nymphal development took significantly longer time in the absence than in the presence of prey at 20 and $25^{\circ} \mathrm{C}$, but the reverse was true at $15^{\circ} \mathrm{C}$. Nymphal mortality was highest at $15^{\circ} \mathrm{C}$ in the presence of prey and it was mainly recorded at the first and second stages. Females oviposited a small number of eggs at all temperatures but not at $30^{\circ} \mathrm{C}$ in the absence of prey. The average number of eggs per female was almost similar with or without prey, being highest at $20^{\circ} \mathrm{C}$, and adult longevity was highest at $15^{\circ} \mathrm{C}$. The results concerning population parameters clearly showed that cucumber with or without prey can not support a population increase of $M$. pygmaeus. However, it seems that $A$. gossypii on cucumber inhibits development of $M$. pygmaeus more than when this aphid species is not present. This adverse effect on this host plant-prey system possibly results from the particular aphid genotype on cucumber, leading to high nymphal mortality, reduced fecundity and short adult life-span of M. pygmaeus.
\end{abstract}

\section{INTRODUCTION}

Predatory bugs of the genus Macrolophus (Hemiptera: Miridae) have been considered as important natural enemies in suppressing whitefly and aphid populations on vegetables (Goula \& Alomar, 1994; Malausa \& TrottinCaudal, 1996; Lykouressis et al., 1999-2000). These predators exhibit diverse feeding habits, consuming several types of prey (aphids, whiteflies, lepidopteran eggs, thrips) as well as plant sap of vegetables. Although they can complete nymphal development feeding solely on plant sap, the role of prey has always been found significant in favoring nymphal development (Tavella \& Arzone, 1996; Perdikis \& Lykouressis, 2000; Lykouressis et al., 2001; Hommes \& ter Horst, 2002; Margaritopoulos et al., 2003) and for the predator's biological and population parameters (Perdikis, 2000; Perdikis \& Lykouressis, 2002).

Aphis gossypii Glover (Hemiptera: Aphididae) is one of the most important insect pests of vegetables and particularly of cucumber. Considering both its resistance to insecticides (Wang et al., 2002), and the lack of effective natural enemies (Alvarado et al., 1997), the evaluation of the potential of the polyphagous predator Macrolophus pygmaeus Rambur as an effective biological control agent of this pest becomes worthwhile.

In an effort to obtain a more complete knowledge of the factors involved in the predator's behaviour and effectiveness as a natural enemy of $A$. gossypii on cucumber, its ability to utilize both prey and plant material indicates that its performance should be studied not only with but also without the presence of prey. Moreover, the thorough investigation of this host plant - prey - predator system could highlight a strategy for a more appropriate use of this predator in future biological control programmes.

Under the above considerations, the objective of the current work was to investigate $M$. pygmaeus performance on cucumber as affected by $A$. gossypii presence. This was conducted by the study on (1) the biological characteristics and (2) the population parameters of the predator M. pygmaeus in the presence and in the absence of $A$. gossypii on cucumber, at an ecologically relevant range of temperatures.

\section{MATERIALS AND METHODS}

A colony of the predator $M$. pygmaeus was initiated from insects collected from a tomato field in the area of Boeotia, central Greece. The cultures were maintained on potted eggplants (cv. Bonica) infested with Myzus persicae (Sulzer) (Hemiptera: Aphididae) in woodframed $(80 \times 80 \times 70 \mathrm{~cm})$ cages. Cultures were kept in a glasshouse at $22.5 \pm 2.5^{\circ} \mathrm{C}$ (mean \pm S.D.) under natural day light.

\section{Egg incubation period and hatching percentage}

Due to the very low fecundity of $M$. pygmaeus on cucumber, it was not possible to estimate the egg incubation period and hatching percentage. For the calculation of the population parameters of $M$. pygmaeus, we used the values for egg incubation period and hatching percentage recorded on eggplant with the prey $M$. persicae, at the respective temperatures. In previous studies (Perdikis, 2000; Perdikis \& Lykouressis, 2002), it was

\footnotetext{
* Corresponding author. Phone: ++3-210- 5294581; fax: ++3-210-5294577.
} 

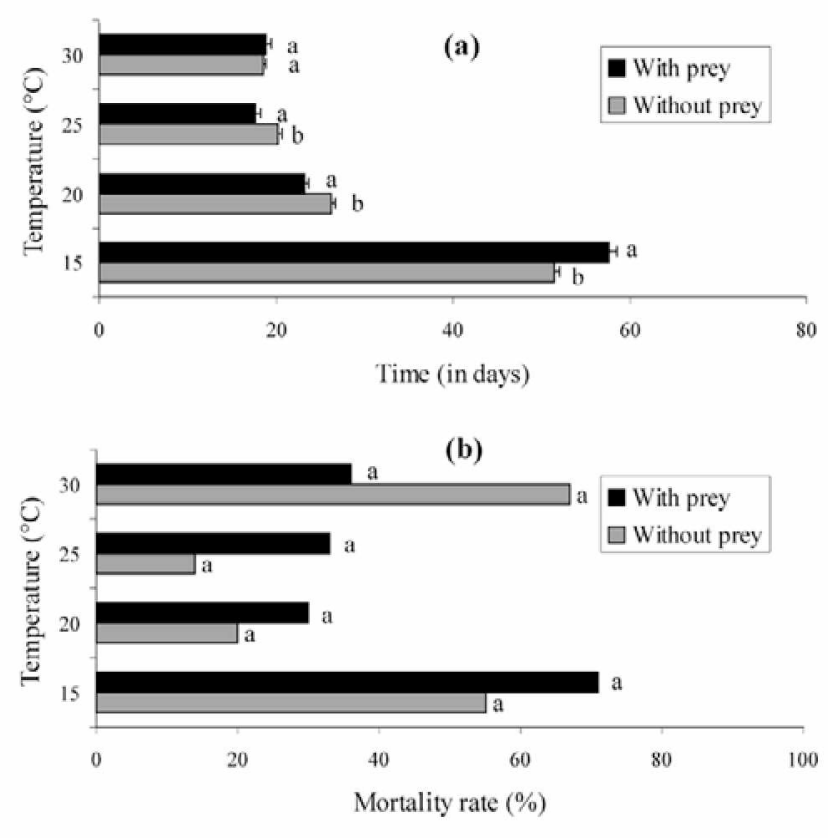

Fig. 1. Developmental period (a) and mortality rate (b) of Macrolophus pygmaeus nymphs on cucumber at various temperatures with or without prey (Aphis gossypii).

Bars at each temperature followed by different letters differ significantly $(\mathrm{P}<0.05)$.

shown that the egg incubation period and hatching percentage were not significantly affected by either the presence/absence of prey or plant type (eggplant or tomato).

\section{Nymphal development}

The development and mortality rate of the nymphs were studied by placing newly emerged nymphs (less than $24 \mathrm{~h}$ old) from the stock cultures individually into Petri dishes. Each Petri dish $(9 \mathrm{~cm}$ in diameter and $1 \mathrm{~cm}$ deep), had a $3 \mathrm{~cm}$ diameter hole in its top, covered with fine muslin, to allow adequate ventilation. A water moistened layer of cotton was placed on the bottom of each dish, with a leaf of cucumber (cv. Brunex) placed upside down. The length and width of the leaf was about 2 and $1 \mathrm{~cm}$, respectively, smaller than the diameter of the dish. The leaves came from young plants with $8-12$ leaves that were grown free of chemicals. The leaf contained A. gossypii or not, depending on the experiment. About 100 to 150 individuals including all stages and adults were present on a single leaf. They were coming from a population which was at the phase of increase.

The experiments were conducted in growth cabinets at 15,20 , 25,30 and $35^{\circ} \mathrm{C}$ with $65 \pm 5 \%$ r.h. and a $16 \mathrm{~L}$ : $8 \mathrm{D}$ photoperiod. In each experiment 20 nymphs (replicates) were used. Development and mortality of the nymphs were recorded at $24-\mathrm{h}$ intervals, but at $35^{\circ} \mathrm{C}$ at intervals of $12 \mathrm{~h}$.

The sex ratio $[q /(q+\delta)]$ of the emerged adults was recorded in all treatments.

\section{Preoviposition period, longevity and fecundity}

Preoviposition period, longevity and fecundity of $M$. pygmaeus, were studied in the presence and in the absence of $A$. gossypii. For that purpose, newly emerged adults, less than 1 -day old were used. One pair of adults was released into a cylinder $(6.5 \mathrm{~cm}$ in diameter and $30 \mathrm{~cm}$ high), made from a transparent $0.4 \mathrm{~mm}$ thick PVC sheet. Each cylinder had two rectangular $(13 \times 5 \mathrm{~cm})$ sides and one top opening covered with muslin.

In each cylinder two cucumber leaves bearing prey or not, depending on the treatment, were placed by inserting the base of their petioles into a layer of foam material firmly attached to the cylinder base. Also, a piece of cucumber stem, 3-5 $\mathrm{mm}$ in diameter and 6-7 cm long, was placed into each cylinder as an ovipositional substrate. This method is described in detail by Perdikis (2002).

Stem and leaves were replenished daily after having been examined under a stereomicroscope for oviposited eggs. Simultaneously, mortality of the adults was recorded and each dead male was replaced by a newly-emerged one. In each treatment about 20 replicates were used. The experiments were conducted in growth cabinets at $15,20,25$ and $30^{\circ} \mathrm{C}, 65 \pm 5 \% \mathrm{r} . \mathrm{h}$. and a 16L : 8D photoperiod.

\section{Data analysis}

Nymphal development, fecundity and longevity were analyzed using analysis of variance (ANOVA) after being logtransformed, and the means were compared using the TukeyKramer HSD test $(p=0.05)$. Survival curves of females were compared using the Wilcoxon test $(p=0.05)$. The differences in mortality rates and sex ratios were compared using a $\chi^{2}$-test after data had been arcsine transformed. The analyses were conducted using the statistical package JMP (version 4.0.2, SAS Institute 2001).

\section{Life tables}

The data obtained were used to construct life tables for $M$. pygmaeus. The age-specific survival rate $\left(1_{x}\right)$ and age-specific fecundity $\left(m_{x}\right)$ were calculated per day. The net reproductive rate $\left(R_{0}\right)$, mean generation time $(T)$ and intrinsic rate of natural increase $\left(\mathrm{r}_{\mathrm{m}}\right)$ were estimated (Birch, 1948; Andrewartha \& Birch, 1954; Southwood, 1978).

\section{RESULTS}

\section{Nymphal development}

The nymphs of $M$. pygmaeus completed their development at all temperatures tested with and without prey, except at $35^{\circ} \mathrm{C}$ where no nymphs completed development (Fig. 1a).

The presence/absence of prey significantly affected the period of development $\left(F_{1,86}=7.89, p<0.007\right)$ and a significantly shorter duration of development was recorded in the presence, than in the absence of prey at 20 and $25^{\circ} \mathrm{C}$. Interestingly, a significant interaction between temperature and presence/absence of prey was recorded $\left(F_{3,86}\right.$ $=15.65, p<0.001)$. This was mainly attributable to the significantly longer period that nymphs needed to complete development at $15^{\circ} \mathrm{C}$, when prey was present than when it was absent (Fig. 1a). The period of development was also significantly affected by temperature $\left(F_{3,86}=\right.$ $36.1, p<0.001)$, and was shortest at $25^{\circ} \mathrm{C}$ in the presence of prey, whereas in prey absence it was shortest at $30^{\circ} \mathrm{C}$.

Nymphal mortality was always higher in the presence than in the absence of prey, although significant differences were not found. At $15^{\circ} \mathrm{C}$ mortality was higher with prey available than with prey absent ( 71 and $55 \%$, respectively). However, at $30^{\circ} \mathrm{C}$ the reverse was true $(36$ and $67 \%$, in the presence and absence of prey, respectively) (Fig. 1b). Nevertheless, the effect of temperature was significant $\left(\chi^{2}=8.55, \mathrm{df}=3, p<0.05\right.$ and $\chi^{2}=20.52, \mathrm{df}=3$, 

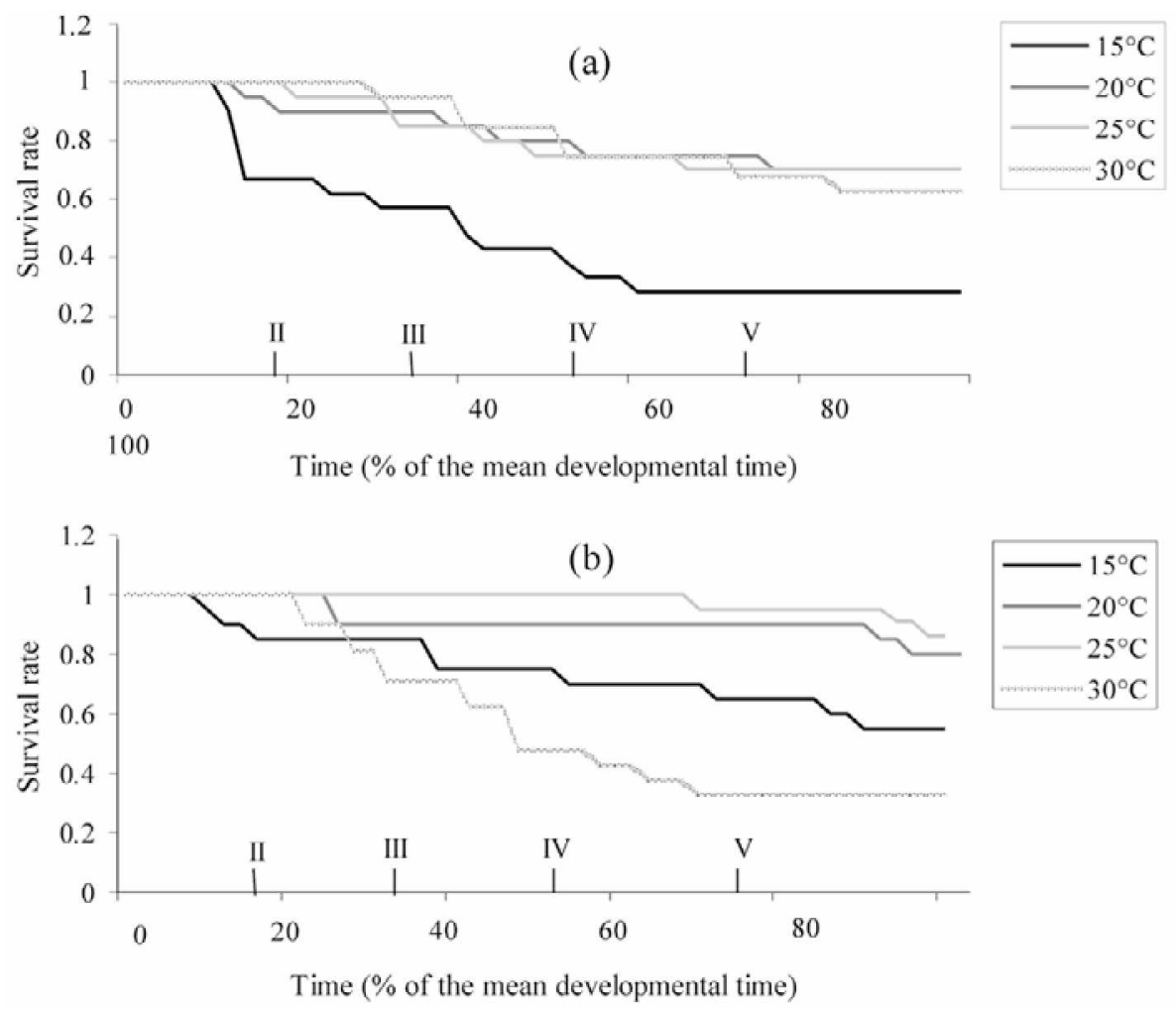

Fig. 2. Survival rate of Macrolophus pygmaeus nymphs on cucumber at various temperatures with (a) or without prey (b) (Aphis gossypii). Numbers above $\mathrm{x}$-axis represent the approximate starting points of each nymphal stage.

$p<0.01$, in the presence and absence of prey, respectively) with lowest mortality recorded at 20 and $25^{\circ} \mathrm{C}$.

The period that each nymph survive was expressed as a percentage of the mean total developmental period. Based on these data, nymphal survival rate curves were constructed at each temperature, either with or without prey (Fig. 2). This figure shows that when prey was available, nymphal mortality at $15^{\circ} \mathrm{C}$ mainly occurred at young stages, whereas in the absence of prey mortality was mainly recorded at older nymphal stages. At 20 and $25^{\circ} \mathrm{C}$ mortality occurred in a more or less similar way either with or without prey. Contrary, at $30^{\circ} \mathrm{C}$ mortality was similar between presence and absence of prey at younger stages, although at the older stages it highly increased when prey was absent.

It was observed that some of the nymphs found dead, when they developed with $A$. gossypii, had their tarsi covered with a sticky material. Similarly, during developmental period, nymphs with exuviae not entirely shed or with third and fourth antennal segments black in colour, were sporadically recorded.

\section{Sex ratio}

Temperature had no significant effect on the sex ratio of $M$. pygmaeus in the presence $\left(\chi^{2}=1.67, \mathrm{df}=3, p>\right.$ $0.5)$ or in the absence of prey $\left(\chi^{2}=1.74, \mathrm{df}=3, p>0.5\right)$ (Table 1). However, the availability of prey led to a sig-

TABLE 1. Sex ratio $(q /(\%+\delta))$, percentage of females $(\%)$ that oviposited and preoviposition period (days \pm SEM) of Macrolophus pygmaeus when fed on cucumber leaves with or without the prey Aphis gossypii, at various temperatures.

\begin{tabular}{|c|c|c|c|c|c|c|}
\hline \multirow{2}{*}{$\begin{array}{c}\text { Temperature } \\
\left({ }^{\circ} \mathrm{C}\right)\end{array}$} & \multicolumn{2}{|c|}{ Sex ratio } & \multicolumn{2}{|c|}{ Oviposited females $(\%)$} & \multicolumn{2}{|c|}{ Preoviposition period } \\
\hline & With prey & Without prey & With prey & Without prey & With prey & Without prey \\
\hline 15 & $\begin{array}{l}0.50 \pm 0.20 \mathrm{Aa} \\
(6)\end{array}$ & $\begin{array}{c}0.33 \pm 0.16 \mathrm{Aa} \\
(9)\end{array}$ & $\begin{array}{l}32 \pm 19 \mathrm{Aa} \\
(6)\end{array}$ & $\begin{array}{l}60 \pm 14 \mathrm{Ba} \\
(12)\end{array}$ & $\begin{array}{c}14.5 \pm 0.7 \mathrm{Aa} \\
(6)\end{array}$ & $\begin{array}{l}19.7 \pm 0.3 \mathrm{Ba} \\
\quad(12)\end{array}$ \\
\hline 20 & $\begin{array}{l}0.56 \pm 0.14 \mathrm{Aa} \\
\quad(14)\end{array}$ & $\begin{array}{l}0.50 \pm 0.13 \mathrm{Aa} \\
\quad(16)\end{array}$ & $\begin{array}{l}60 \pm 14 \mathrm{Aa} \\
(12)\end{array}$ & $\begin{array}{l}55 \pm 15 \mathrm{Aa} \\
(11)\end{array}$ & $\begin{array}{c}11.8 \pm 0.2 \mathrm{Ab} \\
\quad(12)\end{array}$ & $\begin{array}{l}17.4 \pm 0.5 \mathrm{Bb} \\
\quad(11)\end{array}$ \\
\hline 25 & $\begin{array}{l}0.69 \pm 0.13 \mathrm{Aa} \\
\quad(13)\end{array}$ & $\begin{array}{l}0.39 \pm 0.11 \mathrm{Ba} \\
\quad(18)\end{array}$ & $\begin{array}{l}60 \pm 14 \mathrm{Aa} \\
(12)\end{array}$ & $\begin{array}{l}45 \pm 16 \mathrm{Aa} \\
(9)\end{array}$ & $\begin{array}{c}10.3 \pm 0.5 \mathrm{Ab} \\
\quad(12)\end{array}$ & $\begin{array}{c}15.2 \pm 0.3 \mathrm{Bc} \\
(9)\end{array}$ \\
\hline 30 & $\begin{array}{l}0.50 \pm 0.15 \mathrm{Aa} \\
\quad(15)\end{array}$ & $\begin{array}{l}0.33 \pm 0.19 \mathrm{Aa} \\
(6)\end{array}$ & $\begin{array}{c}11 \pm 12 b \\
(2)\end{array}$ & 0 & $\begin{array}{c}11.5 \pm 0.5 \mathrm{Ab} \\
\text { (2) }\end{array}$ & - \\
\hline
\end{tabular}

Means followed by different capital letters in a row for each parameter studied and by different small letters within a column are significantly different $\left(\chi^{2}\right.$-test, Tukey-Kramer HSD test, $\left.P<0.05\right)$.

Numbers in parentheses indicate the number of replicates in each experiment. 

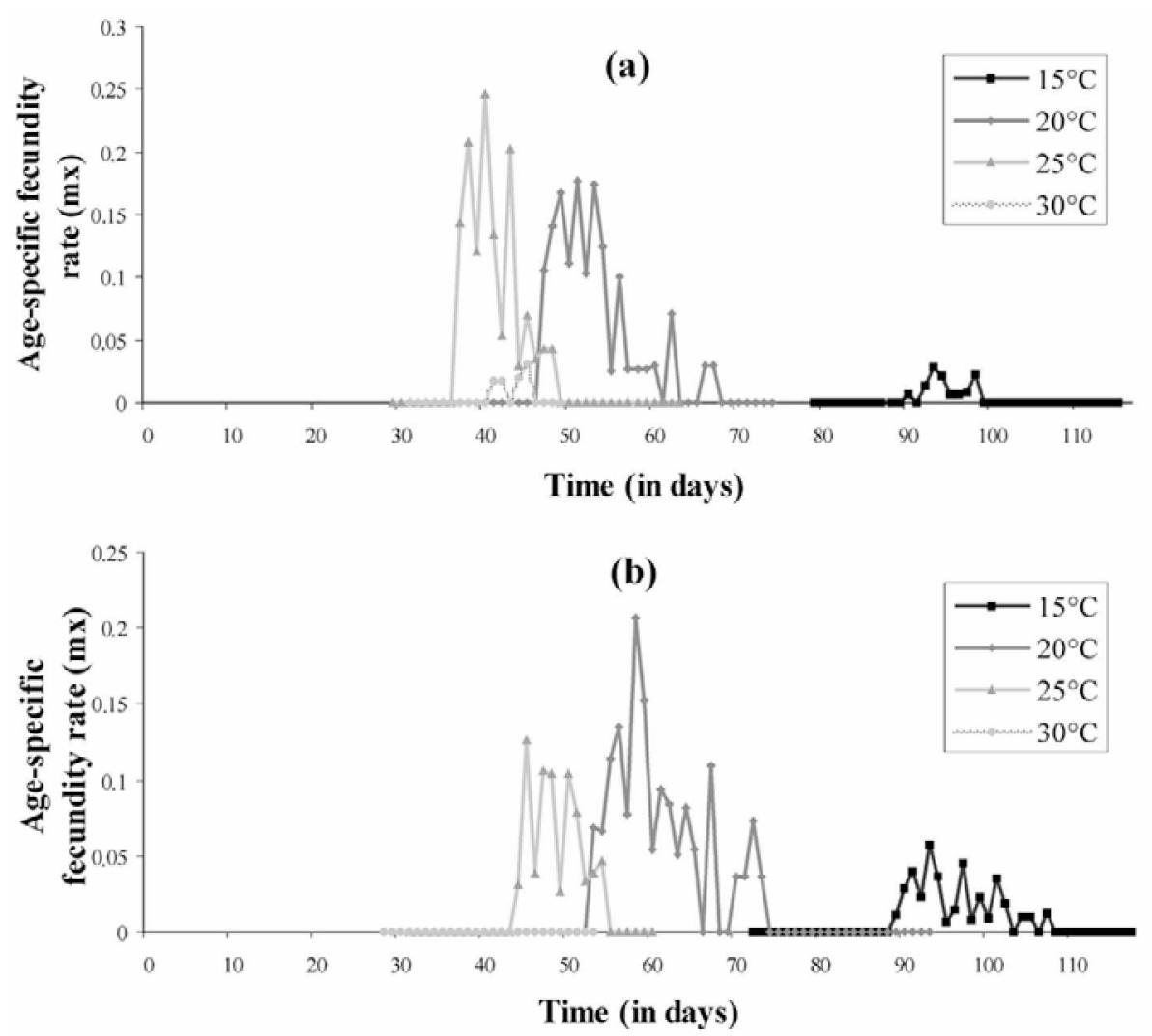

Fig. 3. Age-specific fecundity rate of Macrolophus pygmaeus females fed on cucumber at various temperatures with (a) or without prey (b) (Aphis gossypii).

nificant increase in sex ratio at $25^{\circ} \mathrm{C}\left(\chi^{2}=6.78, \mathrm{df}=1, p\right.$ $<0.01$ ). Most females were produced at 25 and $20^{\circ} \mathrm{C}$, whereas the lowest number of females was recorded at 15 and $30^{\circ} \mathrm{C}$, in the absence of prey.

\section{Preoviposition period}

The recorded percentages of ovipositing females are shown in Table 1. Females of $M$. pygmaeus oviposited at all treatments, except at $30^{\circ} \mathrm{C}$ in the absence of prey. The percentage of females that oviposited was significantly affected by temperature, when prey was present $\left(\chi^{2}=\right.$ $17.27, \mathrm{df}=3, p<0.01)$, but not when prey was not available $\left(\chi^{2}=0.83, \mathrm{df}=2, p>0.50\right)$. It is worth mentioning that the percentage of females that oviposited at $15^{\circ} \mathrm{C}$ was significantly lower in the presence than in the absence of prey (Table 1).

The length of the preoviposition period was significantly affected by presence of prey and temperature, however, no significant interaction between the two factors was recorded $\left(F_{1,56}=206.26, p<0.01 ; F_{2,56}=43.83, p<\right.$ 0.01 and $F_{2,56}=2.42, p>0.1$, respectively). At each temperature, a significantly shorter period was required by females in the presence than in the absence of prey to start ovipositing (Table 1). The shortest preoviposition period was recorded at $25^{\circ} \mathrm{C}$ (averaged 10.3 days and 15.2 days) and the longest at $15^{\circ} \mathrm{C}$ (averaged 14.5 days and 19.7 days) in presence and absence of prey, respectively.

\section{Fecundity}

A significant effect of temperature was found on fecundity $\left(F_{2,56}=8.72, p<0.01\right)$. However, the availability of prey did not significantly affect the fecundity $\left(F_{1,56}=2.09\right.$, $p>0.15)$, whereas the interaction between the two factors was insignificant $\left(F_{2,56}=2.43, p>0.1\right)$. Females were most fecund at $20^{\circ} \mathrm{C}$ (5.6 and 6.5 eggs/female in the presence and in the absence of prey, respectively) (Table 2). In addition, age-specific fecundity rates of $M$. pygmaeus were relatively higher at $20^{\circ} \mathrm{C}$ than at the other temperatures (Fig. 3).

\section{Female longevity}

Longevity of females was significantly affected by presence/absence of prey $\left(F_{1,150}=9.07, p<0.01\right)$ and temperature $\left(F_{3,150}=59.97, p<0.01\right)$, whereas the interaction of those factors was not significant $\left(F_{3,150}=1.59, p>\right.$ $0.19)$. Longevity was longest at $15^{\circ} \mathrm{C}$ (25.9 and 34.1 days) and shortest at $30^{\circ} \mathrm{C}$ (11.6 and 11.2 days), in the presence and absence of prey, respectively (Table 2 ). At 15 and $20^{\circ} \mathrm{C}$, female longevity was longer in the absence than in the presence of prey; whereas at 25 and $30^{\circ} \mathrm{C}$ female longevity was not affected by presence/absence.

The age-specific survival rate of $M$. pygmaeus females, both in the presence and absence of prey, is shown in Figure 4. Generally, survival rate of females remained high for a relatively long period and then declined sharply (Fig. 4). Both in the presence and absence of prey, female survival rate significantly differed between $20-25$ and 

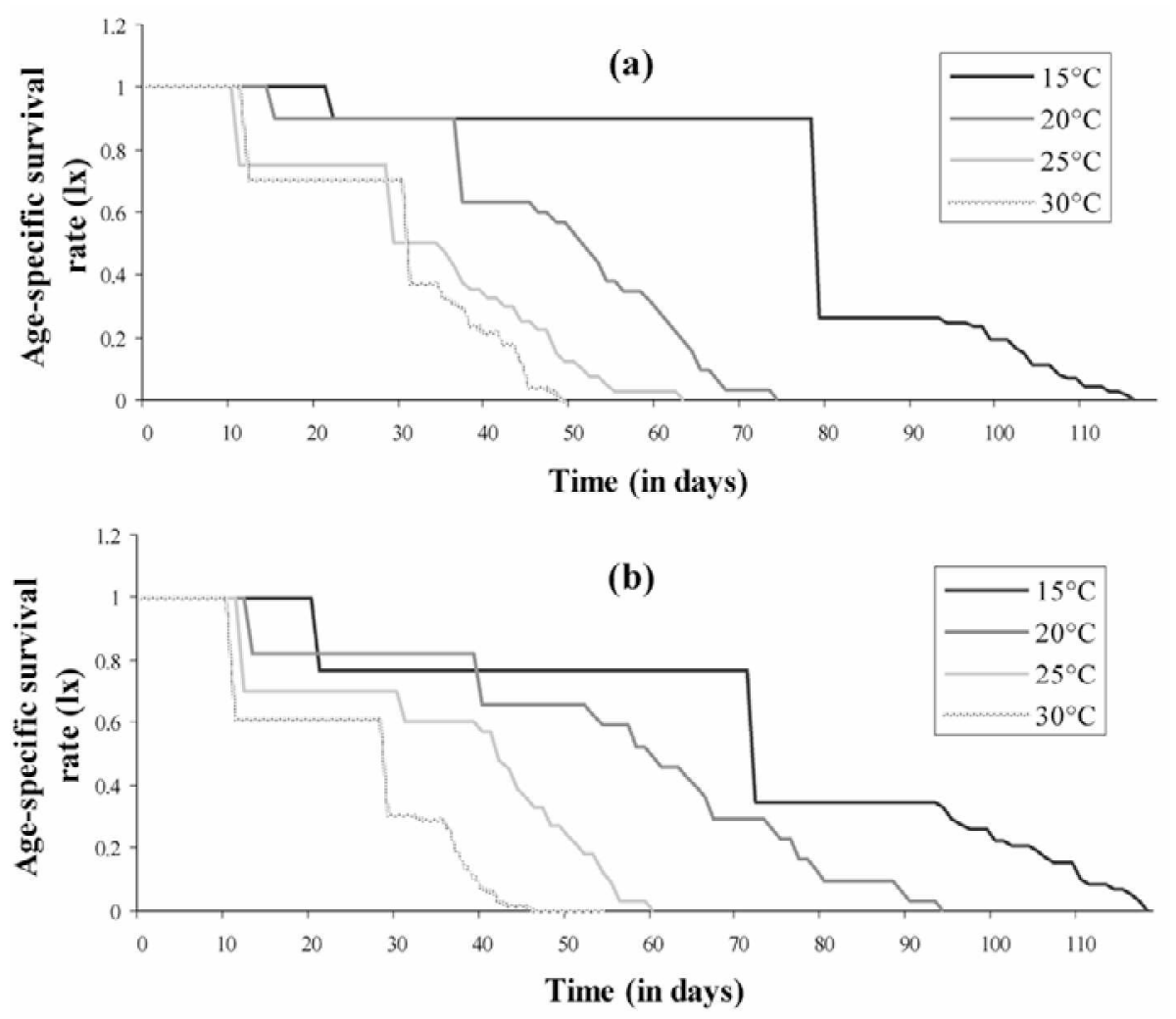

Fig. 4. Age-specific survival rate of Macrolophus pygmaeus females fed on cucumber at various temperatures with (a) or without prey (b) (Aphis gossypii).

$25-30^{\circ} \mathrm{C}\left(\chi^{2}=4.78, \mathrm{df}=1, p<0.03 ; \chi^{2}=6.53, \mathrm{df}=1, p<\right.$ 0.01 in the presence and $\chi^{2}=14.02, \mathrm{df}=1, p<0.01 ; \chi^{2}=$ 18.32 , df $=1, p<0.01$, in the absence of prey, respectively). However, survival rate was not significantly different between 15 and $20^{\circ} \mathrm{C}$ in the presence as well as in the absence of prey $\left(\chi^{2}=1.47, \mathrm{df}=1, p>0.23\right.$ and $\chi^{2}=$ 0.97 , df $=1, p>0.32$, respectively). Dead females bearing a quantity of sticky material on their tarsi, were observed in some cases.

\section{Male longevity}

Longevity of males was significantly affected by presence of prey $\left(F_{1,150}=9.64, p<0.01\right)$ as well as by temperature $\left(F_{3,150}=92.12, p<0.01\right)$. A significant interaction was recorded between those factors $\left(F_{3,150}=\right.$ $3.7, p<0.02$ ), mainly due to the significantly higher longevity in the absence than in the presence of prey at $20^{\circ} \mathrm{C}$. Longevity was highest at $15^{\circ} \mathrm{C}(31.1$ and 36.7 days) and shortest at $30^{\circ} \mathrm{C}(10.8$ and 10.60 days), with the presence and absence of prey, respectively (Table 2 ).

Generally, although males lived longer than females, statistical analyses with factors "sex", "temperature" and "presence/absence of prey" showed no significant difference between female and male longevity $\left(F_{3,300}=1.19, p\right.$ $>0.27$ ).

TABLE 2. Fecundity (eggs/female \pm SEM) and longevity (days \pm SEM) of Macrolophis pygmaeus when fed on cucumber leaves with or without the prey Aphis gossypii, at various temperatures.

\begin{tabular}{|c|c|c|c|c|c|c|}
\hline \multirow{2}{*}{$\begin{array}{c}\text { Temperature } \\
\left({ }^{\circ} \mathrm{C}\right)\end{array}$} & \multicolumn{2}{|c|}{ Fecundity } & \multicolumn{2}{|c|}{ Longevity of females } & \multicolumn{2}{|c|}{ Longevity of males } \\
\hline & With prey & Without prey & With prey & Without prey & With prey & Without prey \\
\hline 15 & $\begin{array}{l}2.7 \pm 0.5 \mathrm{Aab} \\
\quad(6)\end{array}$ & $\begin{array}{l}4.9 \pm 0.4 \mathrm{Aa} \\
\quad(12)\end{array}$ & $\begin{array}{l}25.9 \pm 1.4 \mathrm{Aa} \\
(19)\end{array}$ & $\begin{array}{l}34.1 \pm 1.8 \mathrm{Ba} \\
(20)\end{array}$ & $\begin{array}{c}31.1 \pm 2.3 \mathrm{Aa} \\
(19)\end{array}$ & $\begin{array}{c}36.7 \pm 1.9 \mathrm{Aa} \\
(20)\end{array}$ \\
\hline 20 & $\begin{array}{l}5.6 \pm 0.5 \mathrm{Aa} \\
(12)\end{array}$ & $\begin{array}{l}6.5 \pm 1.1 \mathrm{Aa} \\
(11)\end{array}$ & $\begin{array}{c}22.6 \pm 1.7 \mathrm{Aa} \\
(20)\end{array}$ & $\begin{array}{l}31.3 \pm 2.7 \mathrm{Ba} \\
(20)\end{array}$ & $\begin{array}{c}23.3 \pm 2.5 \mathrm{Ab} \\
(20)\end{array}$ & $\begin{array}{c}35.7 \pm 3.0 \mathrm{Ba} \\
(20)\end{array}$ \\
\hline 25 & $\begin{array}{l}4.2 \pm 1.3 \mathrm{Aab} \\
(12)\end{array}$ & $\begin{array}{l}3.4 \pm 0.4 \mathrm{Aa} \\
(9)\end{array}$ & $\begin{array}{c}17.2 \pm 1.7 \mathrm{Ab} \\
(20)\end{array}$ & $\begin{array}{c}18.6 \pm 1.4 \mathrm{Ab} \\
(20)\end{array}$ & $\begin{array}{c}17.3 \pm 1.3 \mathrm{Ab} \\
(20)\end{array}$ & $\begin{array}{c}18.0 \pm 1.2 \mathrm{Ab} \\
(20)\end{array}$ \\
\hline 30 & $\begin{array}{l}2.0 \pm 1.0 \mathrm{~b} \\
(2)\end{array}$ & - & $\begin{array}{c}11.6 \pm 1.0 \mathrm{Ac} \\
(19)\end{array}$ & $\begin{array}{c}11.2 \pm 0.9 \mathrm{Ac} \\
(20)\end{array}$ & $\begin{array}{c}10.8 \pm 0.8 \mathrm{Ac} \\
(19)\end{array}$ & $\begin{array}{c}10.6 \pm 0.6 \mathrm{Ac} \\
(20)\end{array}$ \\
\hline
\end{tabular}

Means followed by different capital letters in a row for each parameter studied and by different small letters within a column are significantly different $\left(\chi^{2}\right.$-test, Tukey-Kramer HSD test, $\left.P<0.05\right)$.

Numbers in parentheses indicate the number of replicates in each experiment. 
TABLE 3. Life table parameters of Macrolophus pygmaeus when fed with Aphis gossypii or without prey on cucumber, at various temperatures: $R_{0}$, net reproductive rate; $T$, mean generation time (days); $\mathrm{r}_{\mathrm{m}}$, intrinsic rate of increase (/day); DT, doubling time (days).

\begin{tabular}{lcccc}
\hline \multicolumn{5}{c}{ Temperature $\left({ }^{\circ} \mathrm{C}\right)$} \\
\hline $\begin{array}{l}\text { Life table } \\
\text { parameters }\end{array}$ & 15 & 20 & 25 & 30 \\
\hline \multicolumn{5}{c}{ With prey } \\
$\mathrm{R}_{0}$ & 0.027 & 0.653 & 0.409 & 0.010 \\
$\mathrm{~T}$ & 95.262 & 52.408 & 40.573 & 43.470 \\
$\mathrm{r}_{\mathrm{m}}$ & -0.0377 & -0.0081 & -0.0219 & -0.1051 \\
$\mathrm{DT}$ & -18.35 & -85.57 & -31.61 & -6.60 \\
\hline \multicolumn{5}{c}{ Without prey } \\
$\mathrm{R}_{0}$ & 0.108 & 0.735 & 0.201 & - \\
$\mathrm{T}$ & 95.94 & 60.449 & 48.767 & - \\
$\mathrm{r}_{\mathrm{m}}$ & -0.0237 & -0.0044 & -0.0327 & - \\
$\mathrm{DT}$ & -29.78 & -165.035 & -21.197 & - \\
\hline
\end{tabular}

\section{Population parameters}

The value of net reproductive rate $\left(\mathrm{R}_{0}\right)$ was highest at $20^{\circ} \mathrm{C}(0.653$ and 0.735 females/generation, in the presence and absence of prey, respectively) (Table 3 ).

The mean generation time ( $\mathrm{T}$ ) was much shorter at $25^{\circ} \mathrm{C}$ (40.573 and 48.767 days in the presence and in the absence of prey, respectively) than at the other temperatures (Table 3 ). Generally the intrinsic rate of natural increase $\left(\mathbf{r}_{\mathrm{m}}\right)$ - values were found to be negative in all cases, with higher values at $20^{\circ} \mathrm{C}$ (Table 3 ).

\section{DISCUSSION}

Biological and life table parameters of $M$. pygmaeus fed on cucumber with $A$. gossypii, in this study, were inferior to those recorded when the predator was fed with $M$. persicae on eggplant or $T$. vaporariorum on tomato (Perdikis \& Lykouressis, 2002). This adverse effect was reflected by a high percentage of nymphal mortality, highly reduced fecundity and much shorter adult longevity.

A very severe nymphal mortality occurred at 15,20 and $25^{\circ} \mathrm{C}$ compared with that recorded in previous studies on tomato or two varieties of eggplant, ranging from $5-25 \%$, in presence of prey (Perdikis \& Lykouressis, 2000; Lykouressis et al., 2001). Younger nymphs suffered higher mortality than the older ones, which could be attributed to the accumulation of honeydew on their tarsi. Honeydew inhibits either walking and/or feeding of the predator, leading to high nymphal mortality. As the younger nymphs have shorter legs, the possibility to be trapped could be greater and therefore higher mortality would appear. This finding is in accordance with that from a previous study (Perdikis \& Lykouressis, 1997), when a reduced survival of young nymphs was observed on melon with $A$. gossypii at $25^{\circ} \mathrm{C}$. Moreover, Alvarado et al. (1997), working with Macrolophus caliginosus Wagner on cucumber with $A$. gossypii, recorded also high mortality of younger nymphs at $25^{\circ} \mathrm{C}$, although the number of prey used was considerably smaller than that in our experiments. According to Tedeschi et al. (1999) providing early nymphs of $A$. gossypii did not permit $M$. caliginosus to complete development. Adverse effect of honeydew has been also observed on movement of the larvae of Propylea quatuordecimpunctata (L.) (Coleoptera: Coccinellidae) (Banks, 1957) whereas entrapment in whitefly honeydew, reduced the effectiveness of Encarsia formosa Gahan (Hymenoptera: Aphelinidae) (van Lenteren, 1990). In addition, Bush et al. (1993) reported a high nymphal mortality rate of Orius insidiosus (Say) (Hemiptera: Anthocoridae) due to the entrapment in a "sticky substance" produced by $A$. gossypii on beans and which excreted from the cornicles.

The presence of $A$. gossypii caused highly adverse effects on the performance of $M$. pygmaeus females, permitting oviposition of only half of them (Table 1), whereas when $M$. persicae or $T$. vaporariorum had been used as prey on eggplant and tomato, respectively, all the tested females oviposited (Perdikis \& Lykouressis, 2002). In addition, females were much less fecund and showed a considerably reduced lifespan (Table 2) than those feeding on $M$. persicae and $T$. vaporariorum (213.90 and $228.25 \mathrm{eggs} / \mathrm{female}$ at $20^{\circ} \mathrm{C}$, and female longevity averaged 122.40 and 129.35 days at $15^{\circ} \mathrm{C}$, on each host plant respectively) (Perdikis \& Lykouressis, 2002). Similar results have been found by Fauvel et al. (1987), where fecundity of $M$. caliginosus was lower when $A$. gossypii was offered as prey, compared to that observed in the presence of $T$. vaporariorum or $M$. persicae. Moreover, the intrinsic rate of natural increase of $M$. pygmaeus showed negative values as compared to those estimated on eggplant with $M$. persicae or tomato with $T$. vaporariorum $\left(0.0975\right.$ and $0.0969 \mathrm{day}^{-1}$ at $25^{\circ} \mathrm{C}$, on each host plant, respectively) (Perdikis \& Lykouressis, 2002). In general, the sticky material found to cover the tarsi of dead $M$. pygmaeus females, indicates that honeydew could be involved in both short adult longevity and highly reduced fecundity.

In tri-trophic systems adverse effects on predator performance could be due to factors related with prey and/or host plant. As far as the role of prey is concerned, $A$. gossypii appeared in the present work to be an acceptable prey for $M$. pygmaeus, because the predator can complete its development feeding on it, at a significantly higher rate than in the absence of prey, in most cases. The acceptability of $A$. gossypii by $M$. pygmaeus is further supported by the work of Perdikis \& Lykouressis (2000) in which the length of developmental period of this predator on eggplant with $A$. gossypii, was similar to that when $M$. persicae or $M$. euphorbiae were used as prey, under identical experimental conditions. The much better performance of $M$. pygmaeus nymphs when fed with $A$. gossypii, on eggplant than on cucumber could be, at least partially, explained taking into consideration that the honeydew production rate differs among host-plant specific genotypes of $A$. gossypii as was found by Guldemond et al. (1995). It should be mentioned here that in spite of repeated efforts $A$. gossypii colonizing cucumber could not develop on eggplant and vice versa. Honeydew production rate in $A$. gossypii on cotton is affected by tem- 
perature and aphid age whereas temperature influences also the ratio of sugars contained in the honeydew (Henneberry et al., 2000).

As far as the role of host plant is concerned, it seems that in prey absence cucumber supports nymphal development at a similar rate to that of eggplant and tomato, whereas reproduction, albeit lower than that on eggplant, was similar to that on tomato $(21.55$ and 8.28 eggs/female, on eggplant and tomato, respectively, at $20^{\circ} \mathrm{C}$ ) (Perdikis, 2000). In accordance, cucumber infested with $T$. vaporariorum has been found to be a favorable diet for nymphs of $M$. pygmaeus to develop (Perdikis \& Lykouressis, 2000).

Therefore, the reasons why development and reproduction of $M$. pygmaeus are adversely affected by the presence of $A$. gossypil, should be looked for in the specific host plant - prey combination, i.e. cucumber with $A$. gossypii. In fact the presence and feeding of this aphid on cucumber very likely results in the production of high amounts of honeydew deposited on the leaves. Additionally, the dense hairs of cucumber leaves may retain the droplets of honeydew facilitating the entrapment of $M$. pygmaeus, as it was the case in E. formosa (van Lenteren, 1990).

Nymphal mortality appears thus to be caused by mainly the high amounts of honeydew and in a much lesser extent the sticky material from the cornicles. This is also supported by the low nymphal mortality of $M$. pygmaeus when fed with $A$. gossypii on eggplant, on which very little quantity of honeydew is produced.

In conclusion, the performance of an omnivorous predator in a host plant - prey system is affected not only by factors related to the plant or prey species, but rather the interactions of these trophic levels. Our results show that $A$. gossypii on cucumber inhibits $M$. pygmaeus population increase.

ACKNOWLEDGEMENTS. We would like to thank Dr. A. Fantinou, of the Agricultural University of Athens, for suggestions and corrections she made on the manuscript.

\section{REFERENCES}

Alvarado P., Balta O. \& Alomar O. 1997: Efficiency of four Heteroptera as predators of Aphis gossypii and Macrosiphum euphorbiae (Hom.: Aphididae). Entomophaga 42: 215-226.

Andrewartha H.G. \& Brch L.C. 1954: The Distribution and Abundance of Animals. University of Chicago Press, Chicago, $782 \mathrm{pp}$.

BANKS C.J. 1957: The behaviour of individual coccinellid larvae on plants. Anim. Behav. 5: 12-24.

BIRCH L.C. 1948: The intrinsic rate of natural increase of an insect population. J. Anim. Ecol. 17: 15-26.

Bush L., KRING T.J. \& Ruberson J.R. 1993: Suitability of greenbugs, cotton aphids and Heliothis virescens eggs for development and reproduction of Orius insidiosus. Entomol. Exp. Appl. 67: 217-222.

Fauvel G., Malausa J. \& Kaspar B. 1987: Etude en laboratoire des principales characteristiques biologiques de Macrolophus caliginosus (Heteroptera: Miridae). Entomophaga 32: $529-543$.
Goula M. \& Alomar O. 1994 : Miridos (Heteroptera: Miridae) de interes en el control integrado de plagas en el tomate. Guia para su identification. Bol. San. Veg. Plagas 20: 131-143.

Guldemond A.J., Tigges W.T. \& De VRiJeR P.W.F. 1995: Host races of Aphis gossypii (Homoptera: Aphididae) on cucumber and chrysanthemum. Environ. Entomol. 23: 1235-1240.

Henneberry T.J., Forlow L.J., de la Torre T. \& Hendrix D.L. 2000: Cotton aphid (Homoptera: Aphididae) biology, honeydew production, sugar quality and quantity, and relationships to sticky cotton. Southwest. Entomol. 25: 161-173.

Hommes M. \& TER Horst S. 2002: Development and life span of Macrolophus pygmaeus Rambur at different temperatures and influence of host plants and prey. IOBC/WPRS Bull. 25: 103-106.

VAN LeNTEREN J.C. 1990: Biological control in a tritrophic system approach. In: Peters D.C., Webster J.A. \& Chlouber C.S. (eds): Aphid-Plant Interactions: Populations to Molecules. USDA/ARS-Oklahoma State Univ., MP-112, pp. 3-28.

Lykouressis D.P., Perdikis D.Ch. \& Chalkia Ch.A. 1999-2000: The effects of natural enemies on aphid populations on processing tomato. Entomol. Hellen. 13: 35-42.

Lykouressis D.P., Perdikis D.Ch. \& Michalaki M.P. 2001: Nymphal development and survival of Macrolophus pygmaeus Rambur (Hemiptera: Miridae) on two eggplant varieties as effected by temperature and presence/absence of prey. Biol. Control 20: 222-227.

Malaudsa J.C. \& Trottin-Caudal Y. 1996: Advances in the strategy of use of the predaceous bug Macrolophus caliginosus (Heteroptera: Miridae) in glasshouse crops. In: Alomar O. \& Wiedenmann R. (eds): Zoophytophagous Heteroptera: Implications for Life History and Integrated Pest Management. Thomas Say Publ. Entomol., Proc. Entomol. Soc. Am., Lanham., pp. 178-189.

Margaritopoulos J.T., Tsitsifis J.A. \& Perdikis D.Ch. 2003: Biological characteristics of the mirids Macrolophus costalis and Macrolophus pygmaeus preying on the tobacco form of Myzus persicae (Hemiptera: Aphididae). Bull. Entomol. Res. 93: $39-45$.

Perdikis D.CH. 2000: Studies on Biological Parameters and Food Preferences of the Polyphagous Predator Macrolophus Pygmaeus Rambur. PhD Thesis, Agricultural University of Athens, Athens, Greece, $351 \mathrm{pp}$.

Perdikis D.Ch. 2002: A method for laboratory studies on the polyphagous predator Macrolophus pygmaeus Rambur (Hemiptera: Miridae). J. Econ. Entomol. 95: 44-49.

Perdiris D. \& Lykouressis D. 1997 : Rate of development and mortality of nymphal stages of the predator Macrolophus pygmaeus Rambur feeding on various preys and host plants. IOBC/WPRS Bull. 20: 241-248.

Perdikis D. \& LyKouressis D. 2000: Effects of various items, host plants and temperatures on the development and survival of Macrolophus pygmaeus Rambur (Hemiptera: Miridae). Biol. Control 17: 55-60.

Perdikis D.Ch. \& Lykouressis D.P. 2002: Life table and biological characteristics of Macrolophus pygmaeus when feeding on Myzus persicae and Trialeurodes vaporariorum. Entomol. Exp. Appl. 102 : 261-272.

SAS Institute 2001: JMP Start Statistics. A guide to Statistical and Data Analysis. Version 4.0.2. SAS Institute, Cary, N.C.

Southwoon T.R.E. 1978: Ecological Methods. Chapman \& Hall, London, $524 \mathrm{pp}$.

Tavella L. \& Arzone A. 1996: Development of Macrolophus caliginosus and Dicyphus errans on different diets (Rhynchota: Miridae). Proc. XX Int. Congr. Entomol., p. 652.

Tedeschi R., de Clerce P., van de Veire M. \& Tirry L. 1999: Development and predation of Macrolophus caliginosus (Het- 
eroptera: Miridae) on different prey. Med. Fac. Landbouw. Toeg. Biol. Wetensch., Univ. Gent 64/3a: 235-240.

Wang K.-Y., LiU T.-X., YU C.-H., JIANG X.-Y. \& YI M.-Q 2002: Resistance of Aphis gossypii (Homoptera: Aphididae) to fenvalerate and imidacloprid and activities of detoxification enzymes on cotton and cucumber. J. Econ. Entomol. 95: 407-413.

Received February 11, 2003; revised July 11, 2003; accepted August 5, 2003 